\title{
LA POLÍTICA COMERCIAL DE MÉXICO DURANTE EL GOBIERNO DEL PRESIDENTE ENRIQUE PEÑA NIETO (2012-2018)
}

\author{
MEXICO'S TRADE POLICY DURING THE GOVERNMENT \\ OF PRESIDENT ENRIQUE PEÑA NIETO
}

(2012-2018)

\author{
LA POLITIQUE COMMERCIALE DU MEXIQUE \\ SOUS LE GOUVERNEMENT D'ENRIQUE PEÑA NIETO
} (2012-2018)

\author{
Luz María de la Mora Sánchez \\ Centro de Investigación y Docencia Económicas \\ luzmaria.delamora@cide.edu
}

Resumen: El gobierno del presidente Enrique Peña Nieto mantuvo una política comercial abierta y le dio un renovado impulso a la agenda de negociaciones comerciales con su participación en el Tratado Integral y Progresista de Asociación Transpacífica (TIPAT), la modernización del TLC con la Unión Europea y el inicio de negociaciones con algunos países en América Latina, Asia y Medio Oriente. La llegada del presidente Donald Trump colocó la política comercial de México en una posición defensiva. Renegociar el Tratado de Libre Comercio de América del Norte implicó pagar elevados costos para mantener el acceso preferencial a su principal mercado de exportación.

Palabras clave: negociaciones comerciales internacionales; política comercial; comercio exterior; México; tratados de libre comercio; Donald Trump; Enrique Peña Nieto.

Aвstract: The government of President Enrique Peña Nieto maintained an open trade policy and gave a renewed impetus to the trade negotiations agenda with its participation in the Trans-Pacific Partnership Progressive Integration Treaty (TIPAT), the updating of the FTA with the European Union and the initiation of negotiations with some countries in Latin America, Asia and the Middle East. The arrival of President Donald Trump put Mexico's trade policy 
in a defensive position. Renegotiating the North American Free Trade Agreement involved paying high costs to maintain preferential access to its main export market.

Keywords: international trade negotiations; trade policy; foreign trade;

Mexico; free trade agreements; Donald Trump; Enrique Peña Nieto.

\section{Traducción de Gonzalo Celorio Morayta}

Résumé: Le gouvernement d'Enrique Peña Nieto a préservé une politique commerciale ouverte, qu'il a renforcée au moyen de participer dans l'Accord de Partenariat transpacifique global et progressiste (PTPGP), de moderniser l'accord de libre-échange avec l'Union Européenne et d'établir des négociations avec plusieurs de ses voisins en Amérique latine, ainsi qu'avec certains pays de l'Asie et du Moyen Orient. L'arrivée au pouvoir de Donald Trump a placé la politique commerciale du Mexique sur la défensive. Renégocier l'Accord de Libre-Échange Nord-Américain a impliqué des coûts élevés pour que le Mexique puisse conserver l'accès préférentiel à son marché d'exportation le plus important.

Mots clefs: négociations commerciales internationales; politique commerciale; commerce extérieur; Mexique; traités de libre-échange; Donald Trump; Enrique Peña Nieto.

Traducción de BERNARDo MabiRE

Fecha de recepción: diciembre de 2018

Fecha de aceptación: febrero de 2019 
$\mathrm{L}$

A política comercial del gobierno del presidente Enrique Peña Nieto mantuvo continuidad con respecto a la política de apertura y liberalización de gobiernos anteriores. Su administración retomó la construcción, modernización y fortalecimiento de la red de tratados y acuerdos comerciales, lo que concluyó con 12 tratados de libre comercio (TLC) con 46 países. ${ }^{1}$ Sin embargo, a partir de la llegada de Donald J. Trump a la presidencia de EeuU en enero de 2017, la política comercial de México sufrió un severo revés, pues enfrentó una nueva era de proteccionismo que puso en jaque su modelo de desarrollo y crecimiento basado en exportaciones e integración a la economía global, para el cual el mercado de su vecino del norte es un componente vital.

El principal reto a la política comercial mexicana durante el sexenio del presidente Peña Nieto no fue la amenaza de la competencia de China, como lo fue durante el gobierno del presidente Felipe Calderón, sino el proteccionismo impulsado por el mandatario estadounidense. Durante su campaña por la presidencia, el entonces candidato Trump cuestionó de manera sistemática la pertenencia de su país al Tratado de Libre Comercio de América del Norte (TLCAN), herramienta central en el modelo de crecimiento económico de México, y lo calificó como el peor acuerdo negociado por su país. ${ }^{2}$ Prometió a su electorado que de llegar a la Casa Blanca lo renegociaría para rebalancearlo a favor de EEUU y, en caso de no lograrlo, lo denunciaría, lo que habría sido un muy duro golpe para el modelo de desarrollo económico mexicano, fundamentado en su integración productiva regional a América del Norte. Ante el escaso margen de maniobra, Peña Nieto aceptó renegociar el TLCAN a fin de salvaguardarlo, pero

${ }^{1}$ Secretaría de Economía, "Comercio exterior / Países con tratados y acuerdos firmados con México", 10 de mayo de 2015, https://www.gob. $\mathrm{mx} / \mathrm{se}$ /acciones-y-programas/comercio-exterior-paises-con-tratados-yacuerdos-firmados-con-mexico?state=published

2 "El TLCAN, 'el peor tratado de la historia': Donald Trump", Expansión, 14 de septiembre de 2016, https://expansion.mx/2016/09/14/eltlcan-el-peor-tratado-de-la-historia-donald-trump 
también optó por redoblar esfuerzos para profundizar la apertura comercial de México y anunció un plan B, con el que buscó acelerar el ritmo de las negociaciones comerciales de México con socios actuales y nuevos (Corea del Sur, Jordania y Turquía) a fin de diversificar sus lazos de comercio e inversión con otras regiones y países y abrir nuevos mercados a la producción mexicana. ${ }^{3}$

Dando continuidad a la política comercial de México, pero también como una medida defensiva frente a los embates de Trump, la administración de Peña Nieto retomó con vigor la agenda de negociaciones comerciales internacionales. Para propósitos de análisis, dividimos en dos etapas la política comercial del gobierno de Peña Nieto. La primera la ubicamos entre 2012 y 2016 y es de continuidad de la política comercial abierta, durante la cual se buscó revitalizar la agenda de negociaciones comerciales internacionales.

En la segunda etapa (2017-2018), caracterizada por la necesidad de defender su política comercial, México se vio obligado a renegociar los términos de su acceso al mercado estadounidense ante la amenaza de Trump de retirar a su país del TLCAN y de cerrar su mercado mediante la aplicación de medidas proteccionistas avaladas por su propia legislación. En contraste con la administración anterior, en la cual los principales diferendos comerciales se enfocaron en China, el gobierno de Peña Nieto tuvo que hacer frente a las amenazas de EEUU, su principal socio comercial.

Este artículo se estructura en cuatro secciones, en las cuales se analiza, primero, la situación del comercio internacional y de México, en particular, al inicio de la administración de Peña Nieto. En la segunda sección se ponderan los factores de continuidad de la política comercial mexicana en los diversos frentes de negociación a nivel regional y bilateral,

3 “\#100DíasTrump: México sale al mundo en busca de amigos comerciales", Expansión, 29 de abril de 2017, https:/ / expansion.mx/economia/ 2017/04/27/100diastrump-mexico-sale-al-mundo-en-busca-de-amigoscomerciales 
así como los retrocesos en la agenda de negociaciones del TLCAN para enfrentar la posición proteccionista de Trump, quien amenazó con retirar a su país del tratado. En la tercera sección se examina la agenda defensiva del gobierno de Peña Nieto ante los retos que le planteó el proteccionismo de Trump a la política comercial de México. Una última sección se dedica a las conclusiones.

\section{Diagnóstico de LA SITUACión AL INICIO DEL SEXENio}

La política comercial siempre ha causado controversia, pero la creciente fragmentación de la producción y la globalización han exacerbado los ataques al libre comercio y a los acuerdos comerciales regionales. En los años setenta y ochenta, la principal amenaza al comercio internacional fue el proteccionismo que surgió en los países desarrollados. Tanto las recesiones como los cambios estructurales en las economías industrializadas llevaron a que numerosos sectores -confección, calzado, acero, autos, productos electrónicos- demandaran protección ante las crecientes importaciones. ${ }^{4}$

Durante los años noventa se dio una proliferación de acuerdos comerciales regionales que buscaban profundizar la liberalización de las economías más allá de los alcances del sistema multilateral de comercio. Sin embargo, esta proliferación también estuvo acompañada de ataques frontales a la implementación de tales acuerdos, ya que fueron considerados una amenaza a los empleos e industrias nacionales. Tanto sindicatos como grupos ambientalistas hicieron de los acuerdos comerciales, del comercio internacional y de la globalización el blanco de sus ataques y tema central en sus agendas electorales y/o de política pública. Diversos autores han identificado la globalización como una fuente de tensión para el desarrollo e implementación de políticas públicas nacionales

${ }^{4}$ Douglas A. Irwin, Free Trade Under Fire (4ta ed.), Princeton, University Press, 2015, p. 295. 
y han señalado la necesidad de replantear las reglas del comercio internacional. ${ }^{5}$ La llegada del presidente Trump al poder colocó al proteccionismo como la solución a las tensiones generadas por la globalización, lo que obligó a México a actuar en consecuencia y adaptar su modelo integracionista a las demandas de la política comercial de EEUU.

$\mathrm{Al}$ inicio de la administración de Peña Nieto, México tenía 11 TLC con 44 países y 28 acuerdos para la promoción y protección recíproca de las inversiones con 29 países. En este periodo, se sumaron dos TLC: el Acuerdo Comercial de la Alianza del Pacífico y el tratado con Panamá. El TLC Único con Centroamérica remplazó el del Triángulo Norte (El Salvador, Guatemala y Honduras), así como los suscritos con Costa Rica y Nicaragua. ${ }^{6}$

En 2012, México era el décimo tercer actor en el comercio internacional y tanto sus exportaciones como sus importaciones totales representaron $2 \%$ del comercio mundial. Aunque para el final del gobierno de Peña Nieto se mantuvo en el mismo sitio, sus importaciones y exportaciones ampliaron su participación y representaron $2.41 \%$ y $2.31 \%$, respectivamente, del total mundial. ${ }^{7}$

El comercio exterior de México pasó de más de 741000 millones de dólares (mdd) a cerca de 830000 mdd entre 2012 y 2017, pero perdió dinamismo, pues su tasa de crecimiento promedio anual fue de $2.3 \%$, por debajo del ritmo experimentado en el sexenio anterior (2006-2012) de $6.6 \%$.

${ }^{5}$ Véase Dani Rodrik, The Globlization Paradox. Democracy and the Future of the World Economy, Nueva York, WW Norton, 2011, pp. xiv-xv.

${ }^{6}$ El 31 de agosto de 2012 dejaron de estar vigentes el TLC MéxicoNicaragua y el México-Triángulo Norte, para el comercio con El Salvador, y entró en vigor el TLC Único con Centroamérica el $1^{\circ}$ de septiembre de 2013.

7 World Trade Organization, wTo, "Chapter VIII, Statistical Tables", World Trade Statistical Review 2018, p. 124, https://www.wto.org/english/ res_e/statis_e/wts2018_e/wts2018chapter08_e.pdf 


\section{CUADro 1}

\section{México: red de tratados de libre comercio con socios comerciales (2012-2017)}

\begin{tabular}{|c|c|c|c|}
\hline $\begin{array}{c}\text { TLC de México con otros países y fecha de } \\
\text { entrada en vigor }\end{array}$ & $\begin{array}{l}\text { Comercio total, } 2012 \\
\text { (millones de dólares) }\end{array}$ & $\begin{array}{l}\text { Comercio total, } 2017 \\
\text { (millones de dólares) }\end{array}$ & $\begin{array}{l}\text { Crecimiento } \\
2012-2017\end{array}$ \\
\hline $\begin{array}{l}\text { 1. TLCAN (Canadá-EEuU-México) } \\
\text { (1 de enero de 1994)* }\end{array}$ & 494721 & 543389 & $9.84 \%$ \\
\hline 2. Colombia (1 de enero de 1995) & 6469 & 4838 & $-25.21 \%$ \\
\hline 3. Chile (1 de agosto de 1999) & 3754 & 3341 & $-11.01 \%$ \\
\hline $\begin{array}{l}\text { 4. Unión Europea (1 de julio de } \\
2000)^{* *}\end{array}$ & 63040 & 72160 & $14.47 \%$ \\
\hline 5. Israel (1 de julio de 2000) & 852 & 942 & $10.65 \%$ \\
\hline $\begin{array}{l}\text { 6. Asociación Europea de Libre } \\
\text { Comercio (AELC) (1 de julio de 2001) }\end{array}$ & 2595 & 2738 & $5.49 \%$ \\
\hline 7. Uruguay (15 de julio de 2004) & 583 & 591 & $1.34 \%$ \\
\hline 8. Japón (1 de abril de 2005) & 20266 & 22223 & $9.66 \%$ \\
\hline 9. Perú (1 de febrero de 2012) & 1968 & 2024 & $2.88 \%$ \\
\hline \begin{tabular}{|l|} 
10. Centroamérica (El Salvador y \\
Nicaragua: $1^{\circ}$ de septiembre de 2012, \\
Honduras: $1^{\circ}$ de enero de 2013 , Costa \\
Rica: $1^{\circ}$ de julio de 2013 , Guatemala: \\
$1^{\circ}$ de septiembre de 2013 ) \\
\end{tabular} & 9209 & 6772 & $25.85 \%$ \\
\hline $\begin{array}{l}\text { 11. Alianza del Pacífico } \\
\text { Acuerdo Marco (20 de julio de } 2015) \\
\text { Protocolo Adicional al Acuerdo }\left(1^{\circ} \text { de }\right. \\
\text { mayo de } 2016)\end{array}$ & 12188 & 10203 & $-16.29 \%$ \\
\hline 12. Panamá ( $1^{\circ}$ de julio de 2015$)$ & 1219 & 1026 & $-15.84 \%$ \\
\hline
\end{tabular}

Fuente: Sistema de Comercio Exterior, oEA, México. http://www. sice. oas.org/ctyindex/MEX/MEXagreements_s.asp

Cálculos de la Cámara de Comercio Internacional (CCI) basados en estadísticas de UN COMTRADE, International Trade Center (base de datos en línea), https://www.trademap.org/Bilateral_TS.aspx?nvpm=3|484 ||591||TOTAL|||2|1|1|2|2|1|1|1|1

* Incluye Puerto Rico.

** Incluye los departamentos de ultramar de Francia. 


\section{CuAdro 2}

México: exportaciones, importaciones, comercio total y crecimiento anual

\begin{tabular}{|l|c|c|c|c|c|c|c|}
\hline & $\begin{array}{c}\text { Exporta- } \\
\text { ciones } \\
(m d d)\end{array}$ & $\begin{array}{c}\text { Crecimiento } \\
\text { anual } \\
\%\end{array}$ & $\begin{array}{c}\text { Importa- } \\
\text { ciones } \\
(m d d)\end{array}$ & $\begin{array}{c}\text { Crecimiento } \\
\text { anual } \\
\%\end{array}$ & $\begin{array}{c}\text { Saldo de la } \\
\text { balanza } \\
\text { comercial }\end{array}$ & $\begin{array}{c}\text { Comercio } \\
\text { total } \\
(m d d)\end{array}$ & $\begin{array}{c}\text { Crecimiento } \\
\text { anual } \\
\%\end{array}$ \\
\hline 2012 & 370769.9 & 6.1 & 370751.6 & 5.7 & 18.3 & 741521.4 & 5.9 \\
\hline 2013 & 380015.0 & 2.5 & 381210.2 & 2.8 & -1195.1 & 761225.2 & 2.7 \\
\hline 2014 & 396911.7 & 4.4 & 399977.2 & 4.9 & -3065.5 & 796888.9 & 4.7 \\
\hline 2015 & 380549.6 & -4.1 & 395232.4 & -1.2 & -14682.6 & 775782.1 & -2.6 \\
\hline 2016 & 373946.7 & -1.7 & 387064.5 & -2.1 & -13125.3 & 761011.2 & -1.9 \\
\hline 2017 & 409401.1 & 9.5 & 420369.1 & 8.6 & -10875.0 & 829770.2 & 9.0 \\
\hline
\end{tabular}

Fuente: Secretaría de Economía, http:/ /www.economia snci.gob.mx/ sic_php/pages/estadisticas/

El perfil del comercio exterior de México mantuvo su elevada concentración en el mercado de EEUU para sus exportaciones, en tanto que mostró una creciente diversificación de sus importaciones, en las que diversos países de Asia adquirieron un papel cada vez más protagónico. En 2012, EEUU fue el principal destino de las exportaciones mexicanas, a donde se dirigió 77.7\%, seguido de Canadá (2.9\%), España (1.9\%), China (1.5\%), Brasil (1.5\%), Colombia (1.5\%) y Alemania (1.2\%)..$^{8}$ En 2017, 79.8\% de las ventas mexicanas al exterior se destinaron a su vecino del norte, seguido de Canadá $(2.8 \%)$, Alemania $(1.7 \%)$, China $(1.6 \%)$, España (1\%), Japón $(1 \%)$ y Brasil $(0.9 \%) .{ }^{9}$ La dependencia del mercado es-

${ }^{8}$ Cálculos de la Cámara de Comercio Internacional (CCI) basados en estadísticas de International Trade Center, "Lista de los mercados importadores para un producto exportado por México" (base de datos en línea), https://www.trademap.org/Country_SelProductCountry_TS.aspx? nvpm=3|484||||TOTAL |||2|1|1|2|2|1|2|4|1

${ }^{9}$ Cálculos propios utilizando la información comercial de exportaciones e importaciones publicada por el Banco de México, Sistema de Infor- 
tadounidense para el crecimiento de la economía mexicana la hizo altamente vulnerable a las decisiones de política comercial de su vecino al norte, lo que fue mucho más evidente durante la administración de Trump.

México también mantuvo el comercio exterior, junto con la atracción de inversión extranjera directa (IED), como uno de los principales motores para impulsar su crecimiento. De hecho, el índice de apertura comercial (razón entre el comercio total de bienes y servicios y el PIB) se acentuó en el sexenio, llegando a $77 \%$ en 2017, lo que demuestra el peso de ambas variables en la economía mexicana (véase la gráfica 1)

\section{GRÁFICA 1}

México: comercio internacional de bienes y servicios como porcentaje del PIB, 1990-2017

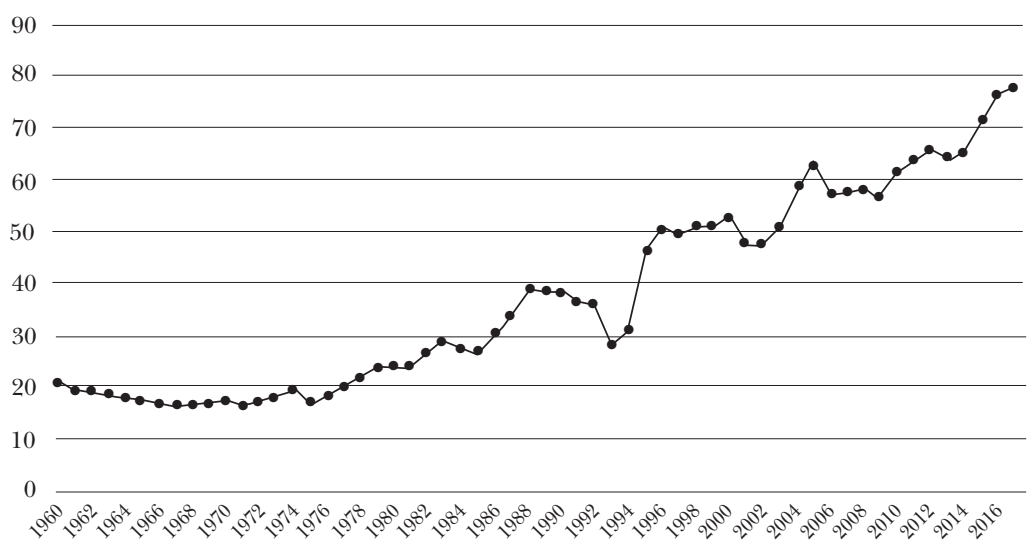

Fuente: Banco Mundial, Data, Trade, \% of GDP, 1990-2017 (base de datos en línea), https://data.worldbank.org/indicator/NE.TRD.GNFS. ZS? end $=2017$ \&locations $=$ MX\&start $=1990$

mación Económica, Balanza de pagos, Exportaciones (base de datos en línea), http:/ /www.banxico.org.mx/SieInternet/consultarDirectorioInternetAction.do? sector $=1 \&$ accion $=$ consultarCuadro\&idCuadro $=\mathrm{CE} 86 \& \mathrm{l}$ ocale $=\mathrm{es}$ 
En cuanto a la IED, durante el gobierno de Peña Nieto, México se mantuvo entre los principales destinos para la captación de capital extranjero. En 2012, ocupó el decimonoveno lugar entre los receptores de IED, concentrando $1.3 \%$ de los flujos de capital a nivel mundial; en 2017 pasó al decimosegundo lugar, con $2.1 \%$. Entre 2013 y junio de 2018, captó 192830.3 mdd (véase el cuadro 3). ${ }^{10}$ Sin embargo, entre julio y septiembre de 2018 la IED cayó $27.7 \%$ por la salida de 4520.5 mdd. ${ }^{11}$

\section{Cuadro 3}

México: inversión extranjera directa realizada por tipo de inversión, en millones de dólares (2013 a enero-junio de 2018)

\begin{tabular}{|c|c|c|c|c|c|c|c|c|}
\hline & \multirow[t]{2}{*}{2013} & \multirow[t]{2}{*}{2014} & \multirow[t]{2}{*}{2015} & \multirow[t]{2}{*}{2016} & \multicolumn{2}{|c|}{2017} & \multirow{2}{*}{$\begin{array}{c}\text { Acumulado } \\
\text { 1999-2018* } \\
\text { Valor }\end{array}$} & \multirow[b]{2}{*}{$\begin{array}{c}\text { Porcentaje } \\
\%\end{array}$} \\
\hline & & & & & Valor & $\begin{array}{c}\text { Porcentaje } \\
\%\end{array}$ & & \\
\hline Total & 48492 & 28672 & 34858 & 29755 & 29695 & 100 & 523984.6 & 100 \\
\hline $\begin{array}{l}\text { Nuevas } \\
\text { inversiones }\end{array}$ & 22448 & 6005 & 13630 & 11027 & 11483 & 39 & 239617.2 & 45.7 \\
\hline $\begin{array}{l}\text { Reinversión de } \\
\text { utilidades }\end{array}$ & 17537 & 16318 & 11630 & 9386 & 9639 & 33 & 156815.1 & 29.9 \\
\hline $\begin{array}{l}\text { Cuentas entre } \\
\text { compañías }\end{array}$ & 8507 & 6349 & 9572 & 9342 & 8627 & 29 & 127552.3 & 24.3 \\
\hline
\end{tabular}

Fuente: Comisión Nacional de Inversiones Extranjeras, CNIE. Informe estadístico sobre el comportamiento de la inversión extranjera directa en México (enero-junio de 2018), p. 12.

${ }^{10}$ Comisión Nacional de Inversiones Extranjeras (CNIE), Informe estadístico sobre el comportamiento de la inversión extranjera directa en México (enerojunio de 2018), México, 2018, p. 6. A septiembre de 2018, la IED acumulada desde 2013 sumó de dólares 198,733.5 millones.

11 Susana González G., "Merma flujo de IED", La Jornada, 14 noviembre de 2018, p. 22. 


\section{LA AGENDA DE NEGOGIACIONES COMERCIALES}

CON EL EXTERIOR: PRINCIPALES ESTRATEGIAS Y ACGIONES

El gobierno de Peña Nieto se propuso "integrar a México en los nuevos bloques de comercio regional" y modernizar los existentes, así como profundizar la integración con América del Norte y América Latina, impulsar el Tratado de Asociación Transpacífico (TPP, por sus siglas en inglés) y la integración económica con la Unión Europea (UE). ${ }^{12}$ En el Plan Nacional de Desarrollo 2013-2018 se establecieron cinco metas nacionales, entre la cuales figura la titulada "México con responsabilidad global”. La estrategia 5.2 de dicha meta reafirmó el "compromiso con el libre comercio, la movilidad de capitales, la integración productiva, la movilidad segura de las personas y la atracción de talento e inversión al país" ${ }^{13}$ y la estrategia 5.3.2 propuso fomentar la integración regional de México, estableciendo acuerdos económicos estratégicos y profundizando los ya existentes.

A su vez, en el objetivo 5 del programa sectorial de la Secretaría de Economía se planteó "incrementar los flujos internacionales de comercio y de inversión, así como el contenido nacional de las exportaciones". ${ }^{14}$ Entre las estrategias trazadas se propuso acceder a nuevos mercados de exportación y consolidar aquéllos en donde ya se tenía acceso preferencial, fortalecer los vínculos comerciales y de inversión con regiones con elevados niveles de crecimiento e incrementar las exportaciones a través de actividades de promoción. También se establecieron cinco "agendas estratégicas" vinculadas con la continuidad del proyecto de apertura comercial: 1) optimización de la red existente de acuerdos comerciales, 2) negociación de nuevos acuerdos, 3) convergencia de tratados,

12 Loc. cit.

13 Gobierno de la República, Plan Nacional de Desarrollo 2013-2018, México, 2013, pp. 151-152.

14 Secretaría de Economía, Programa de Desarrollo Innovador. 20132018. Sectorial, México, Gobierno de la República, p. 54. 
4) fortalecimiento del sistema multilateral del comercio, y

5) defensa legal de los intereses comerciales de México. ${ }^{15}$

\section{La Organización Mundial del Comercio}

México mantuvo su compromiso con un sistema multilateral de comercio abierto y mantuvo una activa participación en la OMC y en las conferencias ministeriales de Bali (diciembre de 2013), Nairobi (diciembre de 2015) y Buenos Aires (diciembre de 2017), así como en diversos órganos, con el ánimo de fortalecer el sistema multilateral de comercio. También recurrió a éste para buscar solucionar controversias comerciales.

Asimismo, participó en la negociación del Acuerdo sobre Facilitación del Comercio (AFC) de la OMC, establecido en la Conferencia Ministerial de Bali de 2013. Éste fue el primer acuerdo multilateral implementado desde la creación de la omC en 1994; México lo aprobó en abril de 2016 y entró en vigor en febrero de 2017.

Como en gobiernos anteriores, la presencia de la misión permanente de México ante la omc desempeñó un papel relevante en las tareas de órganos clave, lo que "representa un reconocimiento de la membresía de la organización al compromiso de México con el Sistema Multilateral del Comercio". ${ }^{16}$ En 2015, el representante permanente de México ante la омс, Fernando de Mateo Venturini, presidió el Consejo General del organismo. Posteriormente, el embajador Rober-

15 Alicia Puyana, "La política comercial de México a lo largo de las dos décadas del thcan: una visión crítica", en Arturo Oropeza García (coord.), TLCAN: 20 años. ¿Celebración, desencanto o replanteamiento?, México, Universidad Nacional Autónoma de México / Instituto de Investigaciones Jurídicas, 2014, p. 111.

${ }^{16}$ Secretaría de Economía, "Presidirá México grupo negociador sobre las normas de la Organización Mundial del Comercio", Comunicado de prensa 0126/18, 8 de marzo de 2018, https://www.gob.mx/se/prensa/presidira-mexico-grupo-negociador-sobre-las-normas-de-la-organizacion-mundial-del-comercio?idiom=es 
to Zapata Barradas, en funciones desde 2017, actuó como presidente, a partir de marzo de 2018, del Grupo sobre Subsidios a la Pesca. ${ }^{17}$

En lo que se refiere al Órgano de Solución de Diferencias de la омc, México recurrió a éste para dirimir la aplicación de aranceles al acero y al aluminio por parte de EEUU al amparo de la sección 232 de su Ley de Expansión Comercial de 1962. ${ }^{18}$ Por su parte, EEuU también inició consultas con México por la imposición de aranceles sobre determinados productos estadounidenses como medida espejo ante los aranceles al aluminio y el acero. México igualmente recurrió a consultas con Costa Rica por las restricciones que le impuso a las importaciones mexicanas de aguacate. ${ }^{19}$

\section{Tratado de Asociación Transpacífico}

En el terreno regional, México tuvo su primera participación en la negociación plurilateral del TPP (integrado por doce países de la cuenca del Pacífico: Brunéi Darussalam, Chile, Nueva Zelandia, Singapur, Australia, Canadá, Estados Unidos, Japón, Malasia, México, Perú y Vietnam) el 2 de diciembre de 2012, durante la $15^{\mathrm{a}}$ ronda. Para cuando México se integró a la negociación, ya se habían tenido avances significativos en algunos textos. ${ }^{20}$

17 World Trade Organization (wTo), "New Negotiating Group on Rules chair kicks off consultations on fisheries subsidies", 28 de marzo de 2018, https://www.wto.org/english/news_e/news18_e/rule_28mar 18_e.htm

18 "DS551: Estados Unidos-Determinadas medidas relativas a los productos de acero y aluminio", https://www.wto.org/spanish/tratop_s/ dispu_s/cases_s/ds551_s.htm

19 "DS524: Costa Rica - Medidas relativas a la importación de aguacates frescos procedentes de México", https://www.wto.org/spanish/tra top_s/dispu_s/cases_s/ds524_s.htm

${ }^{20}$ Guillermo Malpica Soto y Aristeo López, "El capítulo de inversión del TPP: retos y mejoras para México", Puentes (2016), núm. 3, http:// www.ictsd.org/bridges-news/puentes/news/el-cap\%C3\%ADtulo-de- 
Que se haya incorporado se explica, ante todo, por el interés de defender su participación de mercado en EEUU, pero también para asegurar que el contenido mexicano pudiera integrarse en las exportaciones de América del Norte a los países miembros, sobre todo en el Asia Pacífico, bajo el esquema de acumulación de origen. Un tercer objetivo fue crear puentes para acceder a seis nuevos mercados en condiciones preferenciales, aun cuando éstos representan menos de $2 \%$ de su comercio global. El TPP fue visto como la oportunidad de modernizar los TLC existentes con los países socios sin tener que abrir una nueva negociación norteamericana de los acuerdos en vigor. ${ }^{21}$

Para México resultó oneroso negociar este acuerdo en la medida en que tuvo que aceptar aperturas en sectores sensibles, como el textil, la confección, el calzado y de ciertos productos agropecuarios, a países que tienen una muy sólida capacidad exportadora. Dado que México "no es un exportador clave" para la región Asia Pacífico ni un destino prioritario para las inversiones de los nuevos socios de México en el TPP, ${ }^{22}$ el interés central era poder consolidar su integración productiva con EeuU y Canadá. Sin embargo, el destino de este tratado dio un giro cuando el 23 de enero de 2017 el presidente Trump cumplió con su promesa de campaña y retiró a su país. Ello fue un importante revés a la estrategia mexicana de construcción de acuerdos, pues perdió a su principal socio en ese tratado y el balance alcanzado en términos de concesiones ofrecidas y obtenidas se desajustó. Es probable que México no hubiera aceptado participar en el TPP

inversi \% C3\%B3n-del-tpp-retos-y-mejoras-para-m\%C3\%A9xico (consulta del 22 de mayo de 2016).

${ }^{21}$ Luz María de la Mora Sánchez, "El Tratado de Asociación Transpacífico: ¿una puerta en Asia-Pacífico?”, Revista Mexicana de Política Exterior (2016), núm. 108, pp. 195-210.

22 Clyde Prestowitz, "El riesgo de México frente al TPP", en Arturo Oropeza García (coord.), El Acuerdo de Asociación Transpacífico ¿Bisagra o confrontación entre el Atlántico y el Pacífico?, México, Instituto de Investigaciones Jurídicas-UnAm, 2013, p. 468. 
si EEUU no hubiera estado inicialmente en el acuerdo, pues algunos socios le representan una fuerte competencia en diversos sectores.

Sin embargo, su participación le permitió ser parte de la construcción de las nuevas reglas comerciales del siglo XxI. Dado el peso del comercio exterior en la economía mexicana, era coherente buscar ser parte del diseño de estas nuevas reglas a las que, tarde o temprano, México deberá ajustarse si pretende ser parte integral de las cadenas globales de valor.

Modernización del TLCUEM y del TLC con la AELC

Además de la negociación de nuevos acuerdos, en 2013, México y la uE decidieron emprender la modernización de su Acuerdo de Asociación Económica, Concertación Política y Cooperación entre los Estados Unidos Mexicanos, la Comunidad Europea y sus Estados Miembros, o Acuerdo Global, en vigor desde julio de 2000. Conocido también como Tratado de Libre Comercio entre la Unión Europea y México (TLCUEM), se tenía que actualizar para hacer sus reglas más acordes con las tendencias del comercio y la producción globales. ${ }^{23}$

Durante la presidencia de Peña Nieto y en el marco de este tratado, los intercambios de México con la UE, su tercer socio comercial, pasaron de 63000 mdd en 2012 a 72160 mdd en 2017, lo que representó una tasa de crecimiento promedio anual de $2.7 \%$, ligeramente por encima del ritmo de crecimiento de su comercio con el mundo (2.3\%) (véase el cuadro 4).

${ }^{23}$ Roderick Harte, "Modernisation of the trade pillar of the EU-Mexico Global Agreement", septiembre de 2017, http://www.europarl.europa.eu/RegData/etudes/BRIE/2017/608680/EPRS_BRI(2017)608680_ EN.pdf 


\section{CUADro 4}

México: exportaciones, importaciones y comercio total con la UE, en millones de dólares, y tasas de crecimiento anual (2012-2017)

\begin{tabular}{|c|c|c|c|c|c|c|c|}
\hline & Exportaciones & $\begin{array}{c}\text { Crecimiento } \\
\text { anual } \\
\%\end{array}$ & Importaciones & $\begin{array}{c}\text { Crecimiento } \\
\text { anual } \\
\%\end{array}$ & $\begin{array}{c}\text { Saldo de la } \\
\text { balanza } \\
\text { comercial }\end{array}$ & $\begin{array}{c}\text { Comercio } \\
\text { total }\end{array}$ & $\begin{array}{c}\text { Crecimiento } \\
\text { anual } \\
\%\end{array}$ \\
\hline 2012 & 22054.0 & 15.0 & 40986.0 & 8.5 & -18927.1 & 630040.0 & 10.7 \\
\hline 2013 & 19630.3 & -11.0 & 43169.4 & 5.3 & -23473.4 & 62800.0 & -0.4 \\
\hline 2014 & 20222.8 & 3.0 & 44595.1 & 3.3 & -24316.5 & 64817.9 & 3.2 \\
\hline 2015 & 18255.7 & -9.7 & 43743.9 & -1.9 & -25473.4 & 61999.5 & -4.3 \\
\hline 2016 & 19176.3 & 5.0 & 42461.3 & -2.9 & -23039.1 & 61637.7 & -0.6 \\
\hline 2017 & 23153.0 & 20.7 & 49007.4 & 15.4 & -25679.1 & 72160.4 & 17.1 \\
\hline & $\begin{array}{c}\text { Tasa de } \\
\text { crecimiento } \\
\text { promedio } \\
\text { anual }\end{array}$ & 1.0 & & 3.6 & & & 2.7 \\
\hline
\end{tabular}

Fuente: Secretaría de Economía, Sistema de Consulta de Información Estadística por País (base de datos en línea), http://www.economia snci.gob.mx/sic_php/pages/estadisticas/

En la Cumbre ue-celac (Unión Europea-Comunidad de Estados de Latinoamérica y el Caribe), en Santiago de Chile, el 26 de enero de 2013, México y la Unión Europea acordaron la modernización integral de su tratado. En junio de 2015, elaboraron el Reporte de Visión Conjunta, por medio del cual se definieron los objetivos y alcances de la modernización. Las negociaciones comenzaron el 13 y 14 de junio de 2016, en Bruselas, Bélgica, pero el $1^{\circ}$ de febrero de 2017, como reacción al inicio de la presidencia de Trump, se acordó acelerar el proceso de modernización, cuya negociación concluyó con un "principio" de acuerdo en abril de 2018, después de 201 rondas. ${ }^{24}$

${ }^{24}$ Este acuerdo en principio significa que se acordaron los términos generales y será necesario redactar lo acordado, revisar aspectos legales y traducir a 16 idiomas. Posteriormente se firmará y se ratificará por las res- 
La modernización del TLCUEM, además de crear un marco jurídico actualizado, también fue una forma para México de hacer frente al proteccionismo de Trump, mostrando que su agenda de liberalización seguía vigente al poder concretar un acuerdo con el tercer actor en el comercio global. Sin embargo, la modalidad del gobierno de Peña Nieto de concluir acuerdos en principio, si bien puede tomarse como una manera de demostrar su compromiso con un comercio abierto, también creó incertidumbre en el proceso, pues éste se apartó del postulado de paquete completo, que establece que "nada está acordado hasta que todo está acordado". Al realizar anuncios de cierre preliminares quedaron pendientes de definir puntos sensibles de la negociación, como fueron los relacionados con el acceso a mercados de productos agrícolas sensibles y de interés de cada parte, por ejemplo, el tipo de liberalización para el comercio en carne de res o ciertos productos lácteos.

Además de la renegociación del Tlceum, México también lanzó -en enero de 2016, en el marco de la reunión de Davos, Suiza- un proceso de modernización de su TLC con los países de la Asociación Europea de Libre Comercio (AElC) -Islandia, Liechtenstein, Noruega y Suiza-, con miras a ampliar el comercio y la inversión entre ambas partes. Sin embargo, en junio de 2017, después de cuatro rondas de negociaciones, éstas se suspendieron y la actualización no se concretó.

\section{Negociaciones comerciales con América Latina}

La red de TLC y acuerdos de complementación económica (ACE) de México se amplió, aunque no como se esperaba, en América Latina con la integración del tratado con Panamá y

pectivas legislaturas. Víctor Piz, “TLCUEM entraría en vigor en 2020”, El Financiero, 24 de abril de 2018, http:/ / elfinanciero.com.mx/economia/tlcu em-entraria-en-vigor-en-2020 
se fortaleció desde una perspectiva institucional con la entrada en vigor del Acuerdo Marco y el Primer Protocolo Modificatorio del Acuerdo Marco (Acuerdo Comercial) de la Alianza del Pacífico (AP). En lo que se refiere a negociaciones, destacan las iniciadas para ampliar el ACE 6 con Argentina y el ACE 53 con Brasil, sin embargo, dichas conversaciones tampoco fue posible concluirlas.

Con la AP, México, Chile, Colombia y Perú buscaron profundizar su integración económica para impulsar el comercio y la inversión en la región y como una reacción a las agendas proteccionistas de los países del mercosur. Aun cuando los cuatro socios de la AP ya tenían TLC bilaterales y con una cobertura amplia, se decidió profundizar los lazos comerciales de manera que todas las disciplinas y el acceso pudieran concebirse como un esfuerzo regional en vez de sólo la suma de acuerdos bilaterales. En consecuencia, en mayo de 2016 entró en vigor el Protocolo Adicional al Acuerdo Marco de la AP, que establece las reglas para la liberalización del comercio de bienes y servicios, así como para la inversión entre los miembros de la alianza de manera regional. A partir de su entrada en vigor, $92 \%$ de los bienes originarios de la región se decretaron libres de aranceles, mientras que para el $8 \%$ restante, principalmente bienes del sector agrícola, se estableció una apertura de forma gradual.

Con Argentina y Brasil, México renegoció los respectivos apéndices bilaterales del ACE 55 México-Mercosur para el sector automotor con el fin de ampliar por un periodo de cuatro años adicionales ${ }^{25}$ los cupos recíprocos con arancel cero para el comercio de autos. ${ }^{26}$ En 2015, México y Argen-

${ }^{25}$ En marzo de 2012 se postergó la entrada en vigor del libre comercio para automóviles, a través del establecimiento de cupos con arancel cero.

${ }^{26}$ Estos cupos fueron por los siguientes montos: con Argentina, 675 millones de dólares (mdd) el primer año; 592.2 mdd, el segundo; 612.9 mdd, el tercero, y 637.5 mdd, el cuarto. Con Brasil, 1560 mdd el primer año; 1606.8 mdd, el segundo; 1655 md, el tercero, y 1704 mdd, el cuarto. Con ambos países se acordó que a partir del 19 de marzo de 2019 se volvería a aplicar el libre comercio. 
tina, y México y Brasil, nuevamente firmaron sendos protocolos modificatorios a los respectivos apéndices bilaterales del ACE 55, por medio de los cuales se establecieron cuotas incrementales de exportaciones con vigencia entre marzo de 2015 y marzo de 2019, lo que, sin embargo, fue un retroceso con respecto al objetivo inicial de crear una zona de libre comercio para el intercambio en el sector automotor entre México y los países del MERCosur.

También se lanzaron negociaciones con Argentina y Brasil para incluir en sus acuerdos bilaterales (ACE 6 y ACE 53) nuevas disciplinas y profundizar los convenios existentes. Inicialmente, el acercamiento se dio como resultado de los cambios en los gobiernos en ambos países. El presidente de Argentina, Mauricio Macri, dio un giro de 180 grados a la política comercial de su país con respecto a los dos gobiernos previos de los presidentes Néstor Kirchner y Cristina Fernández de Kirchner. En julio de 2016, se acordó iniciar el proceso de negociación para ampliar el ACE 6 y las negociaciones se iniciaron en noviembre de 2016. Se realizaron sólo cuatro rondas, pues México tuvo que destinar sus esfuerzos a la renegociación del TLCAN. Los temas sensibles se ubicaron en la liberalización del comercio en el sector automotor regulado por el ACE 55 y los productos agrícolas y agroindustriales.

Las negociaciones con Brasil para ampliar el ACE 53 comenzaron en noviembre de 2015 y se planteó una amplia agenda de temas que se trataron en nueve rondas. La llegada al poder del presidente Michel Temer colocó la apertura de la política comercial en el centro de la agenda de su administración; México fue ubicado como uno de los socios con quien Brasil buscaba ampliar su acuerdo. ${ }^{27}$

Una vez que el presidente Trump inició su gobierno y quedó clara su amenaza al TLCAN, el acercamiento con ambos socios en el Cono Sur se volvió estratégico para México y

27 Ricardo Della Coletta, "México y Brasil: Dos gigantes de espaldas", ElPaís, 23 de noviembre de 2017, https:/ / elpais.com/internacional/2017/ 11/23/actualidad/1511406216_419092.html 
se consideró acelerar los procesos de negociación. Tanto Argentina como Brasil se consideraron fuentes alternativas de productos agropecuarios a los importados de EEUU, en particular granos, oleaginosas y productos avícolas, y una forma de fortalecer la posición mexicana en la mesa de negociaciones del TLCAN.

Sin embargo, no fue posible concluir las conversaciones con Argentina ni con Brasil, pues México tenía una abultada agenda de negociaciones con varios frentes abiertos, sobre todo en los dos últimos años del gobierno de Peña Nieto, al tiempo que los intereses mexicanos se encontraron con sensibilidades en ambos países sudamericanos que requerían de tiempo, trabajo técnico y consensos políticos para concretar algún resultado, por lo que ambos procesos quedaron truncos.

\section{LA AGENDA COMERGIAL DEFENSIVA (2017-2018)}

El proteccionismo desatado en la era Trump y su amenaza de retirarse del TLCAN exhibieron la gran dependencia y vulnerabilidad de México con respecto al mercado de EEUU para el buen desempeño de su economía. El 26 de abril de 2017, Trump amagó con retirar de manera oficial a su país del TLCAN; no lo hizo, pero mantuvo su intención si la renegociación fracasaba. ${ }^{28}$ EEUU buscó rebalancear el acuerdo a su favor, reducir el déficit comercial, recuperar empleos en la manufactura y desincentivar las inversiones productivas en México.

Previamente al inicio de la negociación, la Secretaría de Economía presentó al Senado el informe de sus objetivos: 1) Fortalecer la competitividad de América del Norte, 2) lograr

28 Mark Landler y Binyamin Appelbaum, "Trump Tells Foreign Leaders That Nafta Can Stay for Now", The New York Times, 26 de abril de 2017, https://www.nytimes.com/2017/04/26/us/politics/nafta-executive-order-trump.html?ref=nyt-es\&mcid=nyt-es\&subid=article 
un comercio regional inclusivo y responsable, 3) aprovechar las oportunidades de la economía del siglo xxi y 4) promover la certidumbre de los mecanismos de solución de controversias para el comercio y las inversiones en América del Norte.

Desde el inicio fueron evidentes las diferencias de diagnósticos, visiones y objetivos entre los tres países. Mientras Canadá y México buscaron modernizar el TLCAN y fortalecer la integración productiva de la región, EEUu planteó que el tratado debía renegociarse pues "le había fallado fundamentalmente a muchos estadounidenses y necesitaba mejoras importantes [dados] los enormes déficit comerciales, los trabajos perdidos en la manufactura, los negocios que han cerrado o se han mudado debido a los incentivos -previstos o no- en el acuerdo actual". ${ }^{29}$

Después de nueve rondas de negociaciones, en las que la fase final se desarrolló de manera bilateral -primero entre EEUU y México y posteriormente entre EEuU y Canadá-, el 31 de agosto de 2017, el gobierno estadounidense notificó a su Congreso que había concluido las negociaciones con México para el Tratado México-Eu-Canadá (TMEC o USMCA, por sus siglas en inglés).$^{30}$ Ello dio el espacio estipulado por la legislación estadounidense (Trade Promotion Authority) para que el presidente Peña Nieto firmara el acuerdo el 30 de noviembre de 2018, justamente al final de su gobierno.

El nuevo tratado presenta claroscuros. ${ }^{31}$ Si bien incluyó nuevas reglas sobre temas como comercio digital y anticorupción, y modernizó, por ejemplo, las relativas a medidas sanitarias y obstáculos técnicos al comercio, presenta

${ }^{29}$ Office of the United States Trade Representative, "Opening Statement of USTR Robert Lighthizer at the First Round of NAFTA Renegotiations", 16 de agosto de 2017, https://ustr.gov/about-us/policy-offices/ press-office/press-releases/2017/august/opening-statement-ustr-robert-0

${ }^{30}$ Canadá y Eevu concluyeron su negociación el 30 de septiembre de 2018, fecha límite para que este último país pudiera enviar el texto del acuerdo a su Congreso y estar en tiempo de firmar el 30 de noviembre de 2018.

${ }^{31}$ El TMEG incluye 34 capítulos, 13 anexos y 13 cartas paralelas. 
serios retrocesos, pues incorporó disposiciones restrictivas para el comercio en América del Norte a las que México tuvo que acceder para salvaguardar el acuerdo. Algunas de las más relevantes se enuncian a continuación:

1. Se estableció un periodo de revisión de 16 años, la cual se inicia en el sexto año, lo que reduce la certidumbre con respecto a la vigencia del acuerdo.

2. La instancia para dirimir diferencias entre inversionistas y el Estado fue significativamente debilitada y se limita a casos entre eEuU y México. Para la mayoría de las inversiones sólo se aplica en casos de violaciones de trato nacional, nación más favorecida y expropiación directa; asimismo, requiere de agotar instancias legales nacionales y deberán pasar tres años antes de poder recurrir a la instancia internacional. Solamente en unos cuántos sectores (energía, telecomunicaciones, infraestructura y transporte) los inversionistas también podrán presentar reclamaciones de nivel mínimo de trato y expropiación indirecta. Así, con esta protección sectorial asimétrica, EEUU buscó desincentivar inversiones manufactureras en México.

3. En el sector automotor se elevó el índice de contenido regional para autos, de $62.5 \%$ a $75 \%$, el más alto negociado en cualquier tratado comercial. Asimismo, de $40 \%$ a $45 \%$ de dicho contenido debe de venir de zonas donde el salario en el sector sea de 16 dólares la hora, lo que deja a México fuera de la posibilidad de que su producción sea considerada y probablemente resultará en que inversiones que podrían haberle sido destinadas se reorienten a EEUu y/o Canadá. Asimismo, al término de la negociación era claro que alrededor de $30 \%$ de las plantas ensambladoras en México no podrían cumplir con el nuevo conjunto de reglas de origen. ${ }^{32}$

${ }^{32}$ Roberto Morales, "Armadoras de Asia y uE contribuirán a cumplir el componente salarial. Votación final del acuerdo en EU, a finales del 
4. En propiedad intelectual, EeuU buscó plasmar su legislación y México aceptó otorgar un periodo de protección de 10 años para los datos clínicos de medicamentos biológicos, lo que va más allá del lapso establecido en la legislación nacional. También aceptó adecuar su sistema de protección de indicaciones geográficas para no restringir la entrada de productos agrícolas (quesos) de EEUU al mercado mexicano como resultado de sus compromisos en el TLCUEM modernizado.

5. México aceptó limitar su acceso al mercado estadounidense en servicios de transporte de recorrido largo para carga internacional como resultado de las presiones del sindicato de transportistas de EEUU (Teamsters), que se opusieron a liberalizar su mercado.

6. En el sector textil se establecieron disposiciones de proveeduría regional, que menoscabarán la competitividad del sector frente a los competidores internacionales.

7. En materia laboral, México accedió a incluir un anexo específico que prevé disposiciones en materia de democracia sindical, negociación colectiva y creación de un registro de elecciones sindicales. Un aspecto novedoso fue que se dispuso que los trabajadores migratorios deben recibir el mismo trato que los nacionales, de acuerdo con las leyes laborales de cada país.

8. EEUU introdujo una disposición (artículo 32.10) que establece que en caso de que alguno de los socios negocie un acuerdo comercial con una economía de no mercado (en clara referencia a China) las otras partes tienen el derecho de revisión y, en caso de no estar de acuerdo con él, pueden retirarse del TMEC, lo que amarra las manos del gobierno mexicano para negociar acuerdos comerciales con países como China. Asi-

año próximo: Casa Blanca”, El Economista, 3 de octubre de 2018, https:/ / www.pressreader.com/mexico/el-economista-m\%C3\%A9xico/201810 $03 / 281483572323672$ 
mismo, por interés de EEUU, se aceptó incorporar una disposición sobre manipulación cambiaria.

Aunque estas disposiciones son contrarias a la profundización de la integración regional y erosionan la competitividad de América del Norte, México estuvo de acuerdo en realizar concesiones onerosas como una forma de salvaguardar el tratado y la relación de comercio e inversión con sus socios de esta región

La aprobación del TMEC en el Congreso de EeuU podría enfrentar una dura batalla, dado que Trump ya no cuenta con una mayoría republicana en la Cámara de Representantes, como resultado de las elecciones del 6 de noviembre de 2018. Existe el riesgo de que, tal como sucedió en 1993 con el TLCAN, los demócratas también quieran imprimir su sello antes de aprobarlo y busquen renegociar partes del acuerdo. De hecho, Nancy Pelosi, líder de la mayoría demócrata en la cámara baja ha señalado que el nuevo acuerdo no ofrece "suficientes garantías de cumplimiento con respecto a la aplicación efectiva de disposiciones laborales y ambientales". ${ }^{33}$ Es de esperarse que el proceso de consideración del TMEC en el Congreso estadounidense esté marcado por el conflicto entre demócratas y republicanos, pues su aprobación sería una victoria política para el presidente Trump, quien podría utilizarla con miras a su reelección en 2020.

De manera paralela a las demandas estadounidenses durante el proceso de renegociación, México se enfrentó a presiones proteccionistas adicionales de EEUU en sectores como el acero y el aluminio. Al amparo de la sección 232 de la Ley de Expansión Comercial de 1962, ${ }^{34}$ EEuU aplicó aranceles de

${ }^{33}$ Bob Bryan, "Trump is about to play a dangerous game of chicken with Democrats to try to ram through his trade deal with Mexico and Canada", Business Insider, 3 de diciembre de 2018

${ }^{34}$ La Ley de Expansión Comercial de 1962 permite al Ejecutivo de EEUU investigar los efectos que las importaciones de un producto pueden tener sobre la seguridad nacional de su país y adoptar las medidas necesarias para eliminar esos efectos negativos. Previamente a ésta, sólo en dos 
$25 \%$ y $10 \%$ a las importaciones de acero y aluminio no sólo para proteger a su industria, sino también como una forma de presión para obtener concesiones en la renegociación del TLCAN.

Otra medida defensiva del gobierno de Peña Nieto fue su incorporación al Tratado Integral y Progresista de Asociación Transpacífico (TIPAT о CPTPP, por sus siglas en inglés). Cuando Eu se retiró del TPP, muchos dieron por muerto ese tratado. Sin embargo, Japón asumió el liderazgo para mantenerlo. El 10 de noviembre de 2017, en el marco de la Cumbre del Foro de Cooperación Económica Asia-Pacífico (APEC) en Danang, Vietnam, se acordó adecuar el TPP y crear el TIPAT, pues mientras EEUU se aislaba, el resto del mundo buscaba seguir construyendo las reglas para el comercio y las inversiones del siglo XXI. El texto del TIPAT es prácticamente el mismo del TPP, excepto por algunas disposiciones relacionadas con su entrada en vigor, la cláusula de denuncia y la de adhesión. El tiPAT se firmó el 8 de marzo de 2018 en Santiago de Chile. ${ }^{35}$ El 24 de abril de 2018, el pleno del Senado mexicano lo aprobó y entró en vigor el 30 de diciembre de 2018, ya durante el gobierno del presidente Andrés Manuel López Obrador.

Tras la salida de EEUU del TPP, en el seno de la AP también se buscó rescatar el acuerdo. Para ello, México propuso negociar TLC con países del TPP -Canadá, Nueva Zelanda, Australia y Singapur- para hacerlos "Estados asociados" mediante la negociación de un tratado "ambicioso y de altos estándares". ${ }^{36}$ El gobierno de Peña Nieto no vio el cierre de dicha negociación.

ocasiones se habían concluido investigaciones con la adopción de medidas en contra de las importaciones de terceros. Éste fue el caso de los embargos petroleros estadounidenses en contra de Irán, en 1979, y de Libia, en 1982.

35 Los textos del TIPAT están disponibles en: https://www.gob.mx/ tpp\#textos.

36 "Estado asociado, un arma de la Alianza del Pacífico contra el proteccionismo", Milenio Digital, 30 de junio de 2017, http://www.milenio. 


\section{Conclusiones}

El gobierno del presidente Peña Nieto mostró patrones de continuidad en su política comercial con respecto a la de gobiernos anteriores al mantener una orientación aperturista, en la que el sector externo siguió siendo piedra angular del crecimiento nacional. Por ejemplo, desde el inicio de su administración participó en la negociación del TPP, la cual se había decidido en el gobierno de Calderón (2012-2018).

Si bien Peña Nieto buscó modernizar y ampliar acuerdos existentes, como los que se tienen con la UE y la AELC, el reto mayor lo representó la llegada al poder de Trump y su imposición de una agenda proteccionista. Sus ataques a México y al TLCAN fueron un muy duro golpe a la integración de México a América del Norte. La amenaza de denuncia del acuerdo obligó al gobierno de Peña Nieto a renegociarlo y a otorgar diversas concesiones que resultaron muy onerosas para el país.

Ante la amenaza Trump, el gobierno de Peña Nieto buscó un plan B para diversificar mercados en el exterior. Sin embargo, este objetivo no alcanzó a materializarse, pues la ampliación prevista de los AcE con Argentina y Brasil no se concretó. Tampoco fue posible concluir la negociación con la AELC ni con los Estados asociados de la Ap dado que quedaron inconclusas las negociaciones comerciales con Corea del Sur, así como con Jordania y Turquía.

La administración de Peña Nieto tuvo como su principal desafío el mantener un acuerdo comercial con sus socios en América del Norte -el Tratado México-Eeuu-Canadá-, aun frente al agresivo proteccionismo de Trump. La agenda comercial de México se vio afectada, pero se resistió a la tentación de adoptar una postura comercial proteccionista que habría resultado en costos aún más elevados para México.

com/politica/alianza_del_pacifico-estado_asociado-libre_comercioacuerdo-nueva_zelanda-australia_0_984501688.html 


\section{Bibliografía}

Banco de México, Sistema de Información Económica, Balanza de pagos, Exportaciones (base de datos en línea), http:/ / www.banxi co. org.mx/SieInternet/consultarDirectorioInternetAction.do?se ctor $=1 \&$ accion $=$ consultarCuadro\&idCuadro $=$ CE86\&locale $=e s$

BRYAN, Bob, "Trump is about to play a dangerous game of chicken with Democrats to try to ram through his trade deal with Mexico and Canada" Business Insider, 3 de diciembre de 2018, https:/ / www.businessinsider.com/trump-nafta-congress-usmca-mexi co-canada-trade-deal-2018-12

Coletta, Ricardo della, "México y Brasil: Dos gigantes de espaldas", El País, 23 de noviembre de 2017, https://elpais.com/interna cional/2017/11/23/actualidad/1511406216_419092.html

"Definen 14 áreas de negociación en el TLcuem, entre México y la Unión Europea", Opportimes, 11 de julio de 2017, https://www. opportimes.com/comercio/definen-14-areas-negociacion-tlcuem-mexico-la-union-europea $\angle$

"El TLCAN, «el peor tratado de la historia»: Donald Trump", Expansión, 14 de septiembre de 2016, https:/ /expansion.mx/2016/ 09/14/el-tlcan-el-peor-tratado-de-la-historia-donald-trump

"Estado asociado, un arma de la Alianza del Pacífico contra el proteccionismo", Milenio Digital, 30 de junio de 2017. http:/ / www.mi lenio.com/politica/alianza_del_pacifico-estado_asociado-libre_ comercio-acuerdo-nueva_zelanda-australia_0_984501688.html

Gobierno de la República, Plan Nacional de Desarrollo 2013-2018, México, Gobierno de la República, 2013, 184 pp.

GonzÁlez G., Susana, "Merma flujo de IED”, La Jornada, 14 noviembre de 2018, p. 22.

HaRTE, Roderick, "Modernisation of the trade pillar of the EUMexico Global Agreement", septiembre de 2017, http://www. europarl.europa.eu/RegData/etudes/BRIE/2017/608680/ EPRS_BRI(2017)608680_EN.pdf

International Trade Center, "Lista de los mercados importadores para un producto exportado por México”, https://www.trademap.org/Country_SelProductCountry_TS.aspx?nvpm=3|484|| ||TOTAL|||2|1|1|2|2|1|2|4|1 
In win, Douglas A., Free Trade Under Fire (4a ed.), Princeton, University Press, 2015, $351 \mathrm{pp}$.

Landler, Mark y Binyamin Appelbaum, "Trump Tells Foreign Leaders That Nafta Can Stay for Now", The New York Times, 26 de abril de 2017, https://www.nytimes.com/2017/04/26/us/ politics /nafta-executive-order-trump.html? ref=nyt-es\&mcid $=$ nyt-es\&subid=article

Malpica Soto, Guillermo y Aristeo López, "El capítulo de inversión del тPр: retos y mejoras para México", en Puentes, 2016, núm. 3, http:/ /www.ictsd.org/bridges-news/puentes/news/elсар\%C3\%ADtulo-de-inversi\%C3\%B3n-del-tpp-retos-y-mejoraspara-m\%C3\%A9xico

Mora SÁnchez, Luz María de la, "El Tratado de Asociación Transpacífico: ¿una puerta en Asia-Pacífico?”, Revista Mexicana de Política Exterior, núm. 108 (2016), pp. 195-210.

Morales, Roberto, "Armadoras de Asia y que contribuirán a cumplir el componente salarial. Votación final del acuerdo en EU, a finales del año próximo: Casa Blanca”, El Economista, 3 de octubre de 2018, https://www.pressreader.com/mexico/el-ec onomista-m\%C3\%A9xico/20181003/281483572323672

Office of the United States Trade Representative, "Opening Statement of USTR Robert Lighthizer at the First Round of NAFTA Renegotiations", 16 de agosto de 2017, https:/ / ustr.gov/aboutus / policy-offices / press-office/ press-releases / 2017/august/ opening-statement-ustr-robert-0 agosto de 2017

Organización Mundial de Comercio, "Solución de diferencias: las diferencias. Diferencias por miembro" (sitio de internet), омC http://www.wto.org/spanish/tratop_s/dispu_s/dispu_by_ country_s.htm

Piz, Víctor, “TLCUEM entraría en vigor en 2020”, El Financiero, 24 de abril de 2018, http://elfinanciero.com.mx/economia/tlcuem entraria-en-vigor-en-2020

Prestowitz, Clyde, "El riesgo de México frente al тPP", en Arturo Oropeza García (coord.), El Acuerdo de Asociación Transpacífico, ¿bisagra o confrontación entre el Atlántico y el Pacífico?, México, Instituto de Investigaciones Jurídicas-unAm, 2013. 
Puyana, Alicia, "La política comercial de México a lo largo de las dos décadas del TLCAN: una visión crítica”, en Arturo Oropeza García (coord.), TLCAN: 20 años. ¿Celebración, desencanto o replanteamiento?, México, Universidad Nacional Autónoma de México / Instituto de Investigaciones Jurídicas, 2014, pp. 97-132.

Rodrik, Ver Dani, The Globlization Paradox. Democracy and the Future of the World Economy, Nueva York, WW Norton, 2011, 346 pp.

Secretaría de Economía, "Comercio exterior / Países con tratados y acuerdos firmados con México", 10 de mayo de 2015, https:/ / www.gob.mx/se/acciones-y-programas/comercio-exterior-paises-con-tratados-y-acuerdos-firmados-con-mexico?state $=$ published

Secretaría de Economía, "Presidirá México grupo negociador sobre las normas de la Organización Mundial del Comercio", 8 de marzo de 2018, https://www.gob.mx/se/prensa/presidiramexico-grupo-negociador-sobre-las-normas-de-la-organiza cion-mundial-del-comercio?idiom=es

Secretaría de Economía, Programa de Desarrollo Innovador. 20132018. Sectorial, México, Gobierno de la República, 94 pp.

Secretaría de Economía, Sistema de Consulta de Información Estadística por País (base de datos en línea), http://www.econo mia snci.gob.mx/sic_php/pages/estadisticas/

"Ven países latinoamericanos oportunidad para exportar a México sin TLCAN", Opportimes, 30 de octubre de 2017, https://www. opportimes.com/comercio/ven-paises-latinoamericanosoportunidad-exportar-mexico-sin-tlcan/

World Trade Organization (wTo), "Chapter VIII, Statistical Tables", World Trade Statistical Review 2018, p. 124, https:/ /www.wto.org/ english/res_e/statis_e/wts2018_e/wts2018chapter08_e.pdf

wTO, "New Negotiating Group on Rules chair kicks off consultations on fisheries subsidies", 28 de marzo de 2018, https://www. wto.org/english/news_e/news18_e/rule_28mar18_e.htm

"\#100DíasTrump: México sale al mundo en busca de amigos comerciales", Expansión, 29 de abril de 2017, https://expansion.mx/ economia/2017/04/27/100diastrump-mexico-sale-al-mundoen-busca-de-amigos-comerciales 
